\title{
Desempenho de vacas leiteiras em pastagem de alfafa suplementada com silagem de milho e concentrado e viabilidade econômica do sistema
}

\author{
[Performance of dairy cows on alfalfa pasture supplemented with corn silage and concentrate \\ and its economic viability] \\ D. Peres Netto ${ }^{1}$, A. de A. Rodrigues ${ }^{2}$, F.S. Wechsler ${ }^{3}$, R.P. Ferreira ${ }^{2}$, F.C. Mendonça ${ }^{2}$, A.R.Freitas ${ }^{2}$ \\ ${ }^{1}$ Departamento de Zootecnia e Desenvolvimento Rural - UFSC \\ Rod. Admar Gonzaga, 1346 \\ 88034-001 - Florianópolis, SC \\ ${ }^{2}$ Embrapa Pecuária Sudeste - São Carlos, SP \\ ${ }^{3}$ Departamento de Produção Animal - Unesp - Botucatu, SP
}

\begin{abstract}
RESUMO
Avaliou-se o efeito da substituição parcial de silagem de milho por pastagem de alfafa no desempenho de vacas leiteiras e na viabilidade econômica do sistema. Utilizaram-se 24 vacas da raça Holandesa, em estádio médio de lactação, em delineamento em blocos ao acaso. Os tratamentos foram: dieta à base de silagem de milho em confinamento, silagem de milho substituída parcialmente por pastejo restrito (PR) e pastejo irrestrito (PI) de alfafa. O sistema de pastejo foi rotacionado, e a quantidade de concentrado igual em todos os tratamentos. A massa de forragem foi de 2.338 e de $1.878 \mathrm{~kg}$ de MS/ha, e a oferta de 1,8 e $4,2 \mathrm{~kg}$ de MS/100kg de peso vivo, nos tratamentos PR e PI, respectivamente. A produção de leite não diferiu entre os tratamentos, cujas médias foram de 25,9; 25,8 e 25,2 litros por vaca por dia no confinamento, no PR e no PI, respectivamente. A produção diária de leite por área foi de 59,3L/ha no PR e de 63,0L/ha no PI, enquanto no confinamento foi de 45,7L/ha. A substituição parcial de silagem de milho por alfafa em pastejo não limitou o desempenho produtivo dos animais e mostrou-se economicamente vantajosa em relação ao confinamento.
\end{abstract}

Palavras-chave: produção de leite, rentabilidade, leguminosa, pastagem

\begin{abstract}
The effect of partial replacement of corn silage for alfafa grazing on dairy cows performance and profitability was evaluated. Twenty-four Holstein dairy cows in mid-lactation were used in a randomized block design. Treatments were: a corn silage-based diet fed on drylot, or partial replacement of corn silage for either restricted alfalfa grazing or unrestricted grazing. A rotational grazing system was used and the amount of concentrate fed was the same in all treatments. Forage availabilities were 2,338 and $1,878 \mathrm{~kg} / \mathrm{ha}$ of dry matter (DM) and offered at 1.8 and $4.2 \mathrm{~kg}$ of DM/100kg of live weight under restricted and unrestricted grazing, respectively. No difference in milk production was observed among treatments, averaging 25.9, 25.8, and 25.2 liters per cow on feedlot, restricted grazing, or unrestricted grazing, respectively. Milk production per hectare was 59.3L/day on restricted grazing and 63L/day on unrestricted grazing, whereas it was $45.7 \mathrm{~L} /$ day on drylot. Partial replacement of corn silage for alfalfa grazing did not limit animal performance and it would be economically advantageous as compared to drylot feeding.
\end{abstract}

Keywords: profitability, milk yield, legume, pasture

Recebido em 16 de agosto de 2010

Aceito em 17 de fevereiro de 2011

Email: dperes@cca.ufsc.br 


\section{INTRODUÇÃO}

A intensificação da produção de leite em pastagens é fundamental para tornar essa atividade competitiva e economicamente rentável. Contudo, o uso de forrageiras de má qualidade e o elevado preço de alimentos concentrados, que representam aproximadamente $30 \%$ do custo total de produção (Anuário...,2008), têm sido apontados como os principais fatores responsáveis pela baixa lucratividade da atividade leiteira. Uma das alternativas mais econômicas para melhorar a nutrição do rebanho leiteiro é o uso de forrageiras produtivas e de boa qualidade. Entre essas, destaca-se a alfafa, por apresentar elevada produtividade, excelente qualidade de forragem e boa aceitabilidade pelo animal, sendo, por isso, indicada para vacas de alto potencial de produção de leite (Rodrigues et al., 2008).

Embora pastagens de alfafa, consorciadas ou não, constituam a base da alimentação dos rebanhos leiteiros na Argentina (Comeron e Romero, 2007), informações sobre seu uso sob pastejo em regiões tropicais na dieta de vacas leiteiras e em sistemas intensivos de produção de leite são escassas. Em condições tropicais e usando vacas Holandesas com média de produção de 6.000 litros de leite por lactação, Vilela et al. (1994) mostraram que a alfafa em pastejo proporcionou média de produção diária de 20 litros por vaca, sem comprometer o peso corporal e a eficiência reprodutiva dos animais.

Em experimento sem adição de concentrado à dieta, no qual se avaliou a alfafa na forma de pastejo, observou-se que a produção de leite foi superior a 5.000 litros por lactação (Comeron et al., 2002). Entretanto, Castilho e Gallardo (1995) afirmaram que, quando o objetivo for incrementar a produtividade leiteira de sistemas baseados em pasto de alfafa com vacas capazes de produzir mais que 6.000 litros de leite por lactação, é necessário elevar a qualidade da dieta mediante o uso de concentrados e de forragens conservadas de boa qualidade. Assim, a alfafa utilizada como parte da dieta poderia contribuir para equilibrar a relação energia:proteína da dieta (Rodrigues et al., 2008), aumentar a produção de leite por área (Jahn et al., 2000a) e reduzir o risco de timpanismo quando comparado ao risco causado pelo uso exclusivo da alfafa em pastejo (Davies e Mendez, 2007). Além disso, Vinholis et al. (2008) observaram, mediante simulação, que a alfafa, associada à suplementação concentrada e volumosa, reduziu o custo de produção final em aproximadamente $15 \%$, em comparação a um sistema em confinamento. Assim, o objetivo deste trabalho foi avaliar o efeito da substituição parcial da silagem de milho por pastagem de alfafa no desempenho de vacas leiteiras e na viabilidade econômica do sistema.

\section{MATERIAL E MÉTODOS}

O trabalho foi realizado na Embrapa Pecuária Sudeste, em São Carlos, SP. O clima da região é subtropical, com inverno seco e verão quente/úmido, apresentando médias de temperatura de $16,3^{\circ} \mathrm{C}$ (julho) a $23^{\circ} \mathrm{C}$ (fevereiro) e média anual de precipitação pluviométrica de $1.502 \mathrm{~mm}$. O solo da área experimental é do tipo argissolo vermelho-amarelo distrófico, de textura média a argilosa (Primavesi et al., 1999). Em abril de 2007, foi feito o preparo do solo e a semeadura da alfafa com a variedade crioula (20kg/ha de sementes). O ensaio foi dividido em dois períodos, um de 15 dias pré-experimental e outro de 84 dias (setembro a dezembro de 2007) experimental, quando foram aplicados, em cobertura, $100 \mathrm{~kg} / \mathrm{ha}$ de $\mathrm{K}_{2} \mathrm{O}$ a cada dois ciclos de pastejo.

Os tratamentos foram: 1) confinamento (CONF), no qual os animais permaneceram confinados em área de descanso, onde receberam dieta completa à base de silagem de milho e concentrado; 2) pastejo restrito (PR), em que o pastejo de alfafa foi limitado a quatro horas por dia - das oito às $10 \mathrm{~h}$ e das 17 às $19 \mathrm{~h}-$ e os animais permaneceram em área de descanso durante $16 \mathrm{~h}$, receberam silagem de milho e concentrado; e 3) pastejo irrestrito (PI), no qual os animais tinham livre acesso ao pasto de alfafa e à área de descanso, onde receberam silagem de milho e concentrado.

A composição das dietas foi calculada de modo a serem similares em proteína bruta (16\%) e em energia ( $70 \%$ de nutrientes digestíveis totais). Foram fornecidos $4,5 \mathrm{~kg}$ de matéria seca (MS) de concentrado por vaca por dia em todos os tratamentos. O fornecimento da silagem foi à vontade, com até $10 \%$ de sobras no tratamento CONF; de 10,5kg de MS por vaca por dia, no tratamento PR; e de 6,6kg de MS por vaca por 
dia, no tratamento PI. Os concentrados foram formulados com diferentes teores de nitrogênio (Tab. 1), para manter constante o teor de proteína bruta da dieta, e amostrados em cada lote processado. A silagem e o concentrado foram fornecidos às 10 e às $16 \mathrm{~h}$. As sobras de silagem foram pesadas uma vez por semana, e a oferta do volumoso foi ajustada conforme $\mathrm{o}$ necessário no tratamento CONF. Também, semanalmente, colheram-se amostras de silagem e das sobras.

Tabela 1. Composição (\%) dos concentrados nos tratamentos expressa na matéria original

\begin{tabular}{lccc}
\hline Ingrediente & $\begin{array}{c}\text { Concentrado A } \\
(43 \% \text { de PB })\end{array}$ & $\begin{array}{c}\text { Concentrado B }^{2} \\
(30 \% \text { de PB })\end{array}$ & $\begin{array}{c}\text { Concentrado C }^{3} \\
(20 \% \text { de PB) }\end{array}$ \\
\hline Milho em grão, moído & 8,50 & 41,30 & 66,30 \\
Farelo de soja & 84,80 & 52,00 & 27,00 \\
Suplemento mineral & 6,64 & 6,64 & 6,64 \\
Monensina sódica & 0,06 & 0,06 & 0,06 \\
\hline
\end{tabular}

${ }^{1}$ Confinamento; ${ }^{2}$ Pastejo restrito (4h por dia); ${ }^{3}$ Pastejo irrestrito.

A alfafa foi manejada em sistema de pastejo rotacionado, com cerca elétrica fixa, e irrigada por sistema de aspersão em malha. O período de ocupação dos piquetes foi de um dia, e o de descanso 30 dias, com taxa de lotação fixa. Os tratamentos PR e PI tiveram duas repetições de área, com 31 piquetes cada. Os piquetes mediam aproximadamente $180 \mathrm{~m}^{2}$ no tratamento PR e $525 \mathrm{~m}^{2}$ no tratamento PI. Quando necessário, foram utilizadas vacas não lactantes para consumo da forragem residual e para rebaixamento da alfafa para 5 a $8 \mathrm{~cm}$ de altura. Nas áreas de descanso, os animais tinham livre acesso a água e a sombra natural.

Foram utilizadas 24 vacas da raça Holandesa em um delineamento em blocos ao acaso, agrupadas de acordo com a produção de leite, idade, peso vivo, número de partos, estádio de lactação e condição corporal, sendo oito vacas por tratamento (quatro animais por repetição de área). A média de peso vivo das vacas foi de $576 \mathrm{~kg}$ (variação de 558 a 594kg), e a de dias em lactação de 176 (variação de 158 a 194 dias) no início do experimento.

Semanalmente, foi estimada a quantidade de forragem disponível e de forragem residual da pastagem, considerando-se a quantidade de forragem cortada antes (forragem disponível) e após o pastejo (forragem residual), a $5 \mathrm{~cm}$ do nível do solo. A amostragem foi feita mediante um quadrado de $1 \mathrm{~m}$ de lado, lançado aleatoriamente quatro vezes nos piquetes de $180 \mathrm{~m}^{2}$ e seis vezes nos de $525 \mathrm{~m}^{2}$. Nessa mesma ocasião, mediu-se a altura da forragem disponível e da forragem residual, tomando-se 20 pontos por piquete.
O consumo diário de matéria seca da alfafa foi estimado a cada semana pela diferença entre a quantidade disponível e a quantidade residual da forragem. A eficiência de utilização da pastagem, por sua vez, foi obtida da razão entre a massa de forragem consumida e a massa de forragem disponível.

Por meio da técnica de simulação de pastejo, descrita por Johnson (1978), amostras do pasto foram coletadas quinzenalmente, em oito pontos por piquete, para determinar a qualidade da forrageira consumida. Com base nessas amostras, foi determinada a relação folha:caule.

Para determinação da matéria parcialmente seca, amostras dos alimentos e das sobras foram secadas em estufa de ventilação forçada a $55^{\circ} \mathrm{C}$, por 72h. Após moagem, as amostras foram analisadas quanto aos teores de MS, proteína bruta (PB), fibra em detergente neutro (FDN), fibra em detergente ácido e lignina, e quanto à digestibilidade in vitro da matéria seca (DIVMS), segundo procedimentos descritos por Nogueira et al. (2005).

As vacas foram ordenhadas mecanicamente às seis e às 19h. A cada semana, foi registrada a produção individual e foram colhidas amostras para análise dos teores de gordura, de proteína e de nitrogênio ureico do leite, realizadas no laboratório da Clínica do Leite, do Departamento de Zootecnia da ESALQ/USP. A produção de leite (PL) foi corrigida para 3,5\% de gordura (PLC), conforme Sklan et al. (1992). A produção diária de leite por área foi obtida pela divisão da produção anual total de leite por 365 dias e pela soma das áreas de silagem e de 
alfafa necessárias para cada tratamento, considerando-se que todos os ingredientes do concentrado foram comprados.

A taxa de lotação potencial foi calculada para 1ha, considerando-se: 1) a média da produção de $2100 \mathrm{~kg} /$ ha de MS de alfafa, obtida nos tratamentos PR e PI, a cada 30 dias; 2) a eficiência de utilização da pastagem de 70\%; e 3) o consumo diário de alfafa nos tratamentos 5,3 e 10,6kg de MS nos tratamentos PR e PI, respectivamente. Para o tratamento em que os animais permaneciam confinados, foram considerados produtividade de silagem de milho de $12 \mathrm{t} / \mathrm{ha}$ por ano e consumo de 17,5kg de MS de silagem por vaca por dia. No início, aos 42 dias e no final do experimento, mediu-se o peso corporal e estimou-se o índice de condição corporal (ICC) dos animais, na escala de 1 a 5 (Wildman et al., 1982).

As mensurações semanais ou quinzenais foram consideradas medidas repetidas no tempo e analisadas pelo procedimento MIXED, do programa computacional SAS (2001). O modelo empregado incluiu os efeitos fixos de tratamento e de semana e a interação de tratamento e semana; e os efeitos aleatórios de áreas dentro de tratamento e os resíduos. Presumiu-se a autocorrelação de primeira ordem entre medidas sucessivas. As médias ajustadas de tratamentos foram comparadas por meio do teste Tukey, com nível de significância de 5\%.

A análise econômica foi realizada para o período de um ano, com base na média de produção de leite obtida por vaca e na taxa de lotação potencial de cada tratamento, levando-se em consideração as áreas necessárias. Para o cálculo do custo de produção, foi considerada a estrutura dos custos operacional efetivo (COE), operacional total (COT) e total (CT) de produção (Matsunaga et al., 1976). No custo de oportunidade da terra, foi considerada a média do valor do arrendamento para produção de cana-de-açúcar (120t/ha) na região de São Carlos, SP. Os preços foram colhidos em janeiro de 2008 e expressos em real (R\$). Para cálculo dos custos da pastagem de alfafa, foram levadas em conta as despesas de formação e de manutenção. Consideraram-se, em média, quatro anos de vida útil para a cultura da alfafa. No cálculo da remuneração anual do capital investido, usou-se a taxa de poupança (6\% ao ano.). Remunerou-se a média, considerando-se o valor inicial mais o valor de sucata dividido por dois, do capital investido em máquinas, implementos e benfeitorias. Para cercas, cochos, bebedouros e conjunto de irrigação, o valor de sucata atribuído foi de zero, e para as demais benfeitorias e máquinas, atribuíram-se $20 \%$ do valor inicial.

Os indicadores de rentabilidade usados na análise foram a margem bruta e líquida, conforme descrito por Lopes et al. (2004). Os preços da mão de obra, da silagem de milho (incluindo o custo de retirada, de transporte e de distribuição), dos demais insumos e das benfeitorias foram obtidos no banco de dados do Centro de Estudos Avançados em Economia Aplicada, cotados em dezembro de 2007, no estado de São Paulo. Para o leite, o farelo de soja e o milho em grão, utilizou-se a média do valor do ano, obtido da mesma fonte.

\section{RESULTADOS E DISCUSSÃO}

Os resultados da análise química dos ingredientes e das dietas utilizadas estão descritos na Tab. 2. As dietas foram planejadas para serem isoproteicas, entretanto, após colheita e análise de amostras no decorrer do experimento, foi observado maior conteúdo proteico nas dietas PR e PI. Esta diferença se deve ao maior teor de $\mathrm{PB}$ da forragem aparentemente consumida em relação à planta inteira.

$\mathrm{Na}$ Tab. 3, apresentam-se os aspectos mais relevantes das condições de pastejo. Era esperado que a massa de forragem (MF) disponível e a altura antes do pastejo fossem similares entre o PR e o PI, pois o manejo da pastagem e as adubações de manutenção realizadas foram semelhantes em ambos os tratamentos. Entretanto, observou-se que a MF disponível e a altura do pastejo foram $24,0 \%$ e 14,0\%, respectivamente, maiores no PR. 
Desempenho de vacas leiteiras...

Tabela 2. Composição química dos ingredientes e das dietas experimentais (porcentagem da matéria seca)

\begin{tabular}{lccccc}
\hline Alimento & PB & FDN & FDA & LIG & NDT \\
\hline Milho em grão, moído & 8,4 & 9,5 & 4.2 & 1,2 & 84,4 \\
Farelo de soja $^{\text {Silagem de milho }}{ }^{1}$ & 50,0 & 14,9 & 8,6 & 0,9 & 80,0 \\
& 7,5 & 47,0 & 25,9 & 2,8 & 67,7 \\
Planta inteira & \multicolumn{2}{c}{ Alfafa } & & & \\
Planta aparentemente consumida $^{2}$ & 25,0 & 37,0 & 29,0 & 5,9 & 64,0 \\
& 26,9 & 35,1 & 26,3 & 5,1 & 70,0 \\
Confinamento $_{\text {Pastejo restrito (4h) }}$ & Dietas aparentemente consumidas & & \\
Pastejo irrestrito & 14,7 & 40,1 & 22,1 & 2,4 & 69,3 \\
\hline PB & 15,1 & 37,7 & 21,4 & 2,4 & 72,0 \\
\hline
\end{tabular}

PB = proteína bruta; FDN = fibra em detergente neutro; FDA = fibra em detergente ácido; LIG = lignina; NDT = nutrientes digestíveis totais estimados segundo o NRC (Nutrient,...2001). ${ }^{1} 39,0 \%$ de matéria seca; ${ }^{2} 20 \%$ de matéria seca em estádio fenológico com 5\% de floração.

Tabela 3. Médias e erros-padrão das características da forragem segundo os tratamentos

\begin{tabular}{|c|c|c|c|c|}
\hline Variável & $\begin{array}{c}\text { Pastejo restrito } \\
(4 \mathrm{~h})\end{array}$ & Pastejo irrestrito & EPM & $\mathrm{P}$ \\
\hline Massa de forragem disponível, kg de MS/ha & $2.338,0$ & $1.878,0$ & & \\
\hline Altura antes do pastejo, cm & 54,5 & 47,7 & 1 & $*$ \\
\hline Massa de forragem residual, kg de MS/ha & $1.154,1$ & $1.070,6$ & 95 & ns \\
\hline Altura do resíduo, cm & 22,4 & 26,9 & 2 & ns \\
\hline Oferta de forragem, kg de MS/100kg peso vivo & 1,8 & 4,2 & 0,3 & $* *$ \\
\hline
\end{tabular}

$\mathrm{EPM}=$ erro-padrão da média.

$\mathrm{P}=$ probabilidade do teste $\mathrm{F}:{ }^{*} \mathrm{P}<0,05 ; * * \mathrm{P}<0,01$; ns = não significativo $(\mathrm{P} \geq 0,05)$.

A oferta de forragem (OF) foi maior no PI. Bargo et al. (2003) afirmaram que, para maximizar a produção de leite por animal, a OF deve ser, aproximadamente, duas vezes o consumo esperado ou $25 \mathrm{~kg}$ de MS por vaca por dia quando usada suplementação. Isto equivale a cerca de 4,2kg de MS/100kg PV por dia, considerando-se uma vaca de $600 \mathrm{~kg}$ de peso vivo. No presente trabalho, a OF no pastejo restrito ficou abaixo do preconizado por esses autores, entretanto a similaridade observada entre o PR e o PI quanto à massa e à altura residual de forragem sugere não ter ocorrido limitação ao consumo de alfafa no PR, pois, em caso contrário, provavelmente os animais teriam rebaixado a forragem mais intensamente neste tratamento. A relação folha:caule do material aparentemente consumido não diferiu entre tratamentos $(\mathrm{P}>0,05)$, sendo de 2,4 e de 2,7 no $\mathrm{PR}$ e no PI, respectivamente, o que sugere que os estratos pastejados foram semelhantes.

A diferença entre tratamentos nos teores de $\mathrm{PB}$, FDN e na DIVMS da planta inteira (25\%, 37\% e $70 \%)$ e da alfafa consumida (26,9\%, 35\% e $73 \%)$ sugere que houve seleção da forragem aparentemente consumida. Reforça esta inferência o fato de a eficiência de pastejo ter sido baixa: $51 \%$ e $43 \%$ nos tratamentos PR e PI, respectivamente. Não se observou interação de tratamentos e de medidas repetidas em nenhuma das variáveis relacionadas ao desempenho. Nas Tab. 4 e 5, são apresentadas as médias de consumo e de produção segundo os tratamentos.

Tabela 4. Médias de consumo de matéria seca dos alimentos e da matéria seca total

\begin{tabular}{|c|c|c|c|}
\hline Consumo & Confinamento & Pastejo restrito (4 h) & Pastejo irrestrito \\
\hline Alfafa, kg/vaca/dia & - & $5,3^{\mathrm{Y}}$ & $10,6^{\mathrm{X}}$ \\
\hline Silagem de milho kg/ vaca/ dia ${ }^{1}$ & 17,5 & 10,5 & 6,6 \\
\hline Concentrado kg/vaca/dia ${ }^{1}$ & 4,5 & 4,5 & 4,5 \\
\hline Total, kg/vaca/dia & 22,0 & 20,3 & 21,7 \\
\hline Total, \% do peso vivo & 3,8 & 3,6 & 3,7 \\
\hline
\end{tabular}

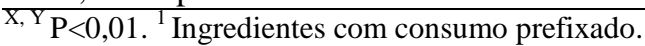


O consumo de MS de alfafa foi duas vezes maior no PI; esta diferença era esperada, em razão da menor oferta de silagem, da maior oferta de forragem (Tab. 3) e do maior tempo disponível para pastejo neste tratamento. O consumo de alfafa, 5,3, e o de 10,6kg de MS por vaca por dia no PR e no PI, respectivamente, representaram aproximadamente $25 \%$ e $50 \%$ da dieta total. Muitos são os fatores que interferem no consumo de MS em pastagens, incluindo a massa de forragem pré-pastejo e a OF (Bargo et al., 2003). Jahn et al. (2000b) mostraram que valores de massa de forragem de $1.500 \mathrm{~kg}$ de MS/ha, o que equivaleu à $\mathrm{OF}$ de $1,2 \mathrm{~kg}$ de MS/100kg de PV, limitaram o consumo de alfafa de vacas leiteiras. Neste trabalho, os valores de MF disponível e de OF encontrados (Tab. 3) estão acima desse limite, e isso sugere que o CMS de alfafa não foi limitado pela oferta de forragem.

A média de CMS total (alfafa, silagem e concentrado) foi de $21 \mathrm{~kg}$ por vaca por dia e de 3,7\% do PV (Tab. 4). Segundo o NRC (Nutrient,...2001), no caso de vacas de raças grandes, como a Holandesa, e de produção diária de leite de $25 \mathrm{~kg}$ em estádio médio de lactação, espera-se consumo diário de 19,6kg de MS por animal, valor próximo às médias observadas, o que sugere que o CMS total não limitou o desempenho dos animais.

Tabela 5. Médias e erros-padrão da produção de leite (PL) e da produção de leite corrigida para 3,5\% de gordura (PLC), da composição química do leite, da variação do peso vivo e do índice de condição corporal dos animais segundo os tratamentos

\begin{tabular}{lccc}
\hline Variável & Confinamento & Pastejo restrito (4 h) & Pastejo irrestrito \\
\hline PL, litros/vaca/dia & $25,4 \pm 1$ & $25,8 \pm 1$ & $25,2 \pm 1$ \\
PLC, kg/vaca/dia & $24,9 \pm 1$ & $25,0 \pm 1$ & $23,2 \pm 1$ \\
Gordura \% & $3,3 \pm 0,06$ & $3,0 \pm 0,07$ & $3,4 \pm 0,09$ \\
Proteína, \% & $3,4 \pm 0,02$ & $3,3 \pm 0,02$ & $3,4 \pm 0,02$ \\
Nitrogênio ureico, mg/dL & $12,2 \mathrm{~A} \pm 0,5$ & $16,2 \mathrm{~B} \pm 0,5$ & $18,0 \mathrm{~B} \pm 0,5$ \\
Variação no peso vivo, kg/vaca/dia & $0,571 \pm 0,07$ & $0,455 \pm 0,06$ & $0,620 \pm 0,06$ \\
Índice de condição corporal & $2,8 \pm 0,1$ & $2,7 \pm 0,1$ & $3,0 \pm 0,1$ \\
\hline
\end{tabular}

Médias com letras distintas na mesma linha diferem entre si pelo teste Tukey a 5\% de probabilidade.

As médias de PL e PLC não diferiram entre tratamentos (Tab. 5), portanto a substituição parcial da silagem de milho por pasto de alfafa não prejudicou a produção de leite. A produção de leite por área no CONF, no PR e no PI foi de 45,7, 59,3 e 63,0 litros/ha por dia, respectivamente.

A taxa de lotação potencial no CONF, no PR e no PI foi, respectivamente, de 2,0, 9,0 e 5,0 animais/ha. Se for considerada a participação de silagem na dieta dos animais em pastejo, a taxa de lotação equivaleria a 3,0 e 3,2 unidades animais por hectare no PR e no PI, respectivamente. Essa diferença se deve à produção de MS por área das forrageiras e ao consumo diário de alfafa ou de silagem em cada tratamento. No trabalho de Vilela et al. (1994), o pastejo exclusivo de alfafa, sem suplementação, permitiu PL de $20 \mathrm{~kg}$ por vaca por dia e PL por área de $51 \mathrm{~kg} / \mathrm{ha}$ por dia. Esses resultados são mais baixos que os encontrados no presente trabalho, e isso indica que a suplementação com silagem e concentrado incrementou tanto a produção de leite por animal como a produção por área. Salado et al. (2007) afirmaram que dieta à base de pasto de alfafa e silagem, em diferentes proporções durante o ano, e adequada suplementação com concentrado, seria o esquema alimentar mais viável e mais sustentável para atingir eficiência produtiva e econômica, em sistemas de produção baseados em alfafa.

Não se observaram diferenças nos teores de gordura e de proteína do leite (Tab. 5), o que é esperado, uma vez que as produções de leite foram semelhantes e a quantidade de concentrado foi moderada $(4,5 \mathrm{~kg}$ de MS por vaca por dia).

A concentração de $\mathrm{N}$ ureico no leite foi, em média, $28,7 \%$ maior quando os animais tiveram acesso à alfafa, o que pode ser atribuído à elevada degradação ruminal da proteína desta forrageira. Segundo Castilho et al. (2007), a 
degradação ruminal da proteína de forragens frescas, especialmente de leguminosas, como a alfafa, é alta e normalmente excede os requisitos de amônia das bactérias fibrolíticas do rúmen. Esse excesso de amônia ruminal acarreta alta concentração de nitrogênio amoniacal no rúmen (Castilho e Gallardo, 1995) e de nitrogênio não proteico no plasma e no leite (Castilho et al., 2007). Butler (2004) observou que as taxas de prenhez de vacas leiteiras reduziram-se em aproximadamente $20 \%$, quando o $\mathrm{N}$ ureico no leite (NUL) ultrapassou 19mg/dL. Embora a concentração de NUL encontrada no presente trabalho (Tab. 5) esteja abaixo desse valor crítico, os tratamentos com alfafa redundaram em valores de nitrogênio ureico próximos ao limite acima do qual ocorreria prejuízo reprodutivo.
Não se observou efeito de tratamento sobre a variação de peso vivo (Tab. 5), que foi positiva, e isso indicou que as vacas estavam em balanço energético positivo. Corrobora esta inferência o aumento da média do ICC no decorrer do experimento: 2,6 no início, 2,7 aos 42 dias e 3,1 no final. Assim, é de se esperar que a reprodução tampouco fosse prejudicada por deficiência da condição corporal.

$\mathrm{Na}$ Tab. 6, apresentam-se as estimativas de custos de produção e de indicadores de rentabilidade dos sistemas avaliados. Para efeito comparativo, somente os dois fatores de maior participação no custo operacional efetivo silagem e concentrado - são apresentados.

Tabela 6. Estimativa dos custos de produção de leite segundo os tratamentos

\begin{tabular}{|c|c|c|c|}
\hline Variável & Confinamento & Pastejo restrito (4 h) & Pastejo irrestrito \\
\hline Receita total (RT), R\$/L ${ }^{1}$ & 0,650 & 0,650 & 0,650 \\
\hline Custo operacional efetivo (COE), $\mathrm{R} \$ / \mathrm{L}^{2}$ & 0,413 & 0,316 & 0,292 \\
\hline - Silagem & 0,186 & 0,110 & 0,070 \\
\hline - Concentrado & 0,116 & 0,104 & 0,095 \\
\hline Custo operacional total (COT), $\mathrm{R} \$ / \mathrm{L}^{3}$ & 0,426 & 0,337 & 0,325 \\
\hline Custo total (CT), R $\$ / \mathrm{L}^{4}$ & 0,459 & 0,370 & 0,364 \\
\hline Lucro, $\mathrm{R} \$ / \mathrm{L}^{5}$ & 0,191 & 0,279 & 0,286 \\
\hline Margem bruta, $\mathrm{R} \$ / \mathrm{L}^{6}$ & 0,237 & 0,334 & 0,358 \\
\hline Margem líquida, $\mathrm{R} \$ / \mathrm{L}^{7}$ & 0,223 & 0,313 & 0,324 \\
\hline
\end{tabular}

${ }^{1} \mathrm{RT}$ = venda do leite; ${ }^{2} \mathrm{COE}=$ mão de obra, manutenção das pastagens, silagem, concentrado, medicamentos, material de ordenha, transporte do leite, energia elétrica (irrigação), inseminação artificial, impostos e taxas, reparos de máquinas e de benfeitorias; ${ }^{3} \mathrm{COT}=\mathrm{COE}+$ depreciação de benfeitorias, de máquinas e da pastagem; ${ }^{4} \mathrm{CT}=\mathrm{COT}$ + remuneração do capital investido e custo de oportunidade da terra; ${ }^{5}$ Lucro $=\mathrm{RT}-\mathrm{CT} ;{ }^{6}$ Margem bruta $=\mathrm{RT}-$ $\mathrm{COE} ;{ }^{7}$ Margem líquida $=\mathrm{RT}-\mathrm{COT}$.

Ocorreu redução de aproximadamente $30,6 \%$ e 41,5\% no COE do pastejo restrito e do pastejo irrestrito, respectivamente, em comparação ao COE do confinamento. Este resultado pode ser explicado pela redução da participação da silagem e do concentrado no COE, componentes onerosos da dieta, à medida que aumentou a participação da alfafa na alimentação. Além disso, a redução do teor proteico do concentrado de $43 \%$ no CONF para $30 \%$ no PR ou $20 \%$ no PI (Tab. 1) contribuiu para diminuir o custo deste componente da dieta. Com vacas em estádio de lactação semelhante ao do presente trabalho, Salado et al. (2007), ao compararem dieta à base de pasto de alfafa mais $9,5 \mathrm{~kg}$ de concentrado com outra à base de silagem de sorgo e feno mais $6 \mathrm{~kg}$ de concentrado, observaram que o custo de alimentação foi $30 \%$ menor no tratamento com alfafa em pastejo. $\mathrm{Na}$ composição do COE, a silagem e o concentrado foram os fatores mais representativos. Ambos representaram 73,0\% no tratamento CONF, $68,0 \%$ no tratamento PR e 57,0\% no tratamento PI do custo de alimentação. Tupy et al. (2000) mostraram que esses dois componentes são responsáveis por $77 \%$ do custo de alimentação, valor superior ao deste trabalho.

A diferença entre o COT dos tratamentos foi menor do que a observada no COE. Isso se deve à maior participação da depreciação das benfeitorias, das máquinas e do pasto no COE. Não obstante, os tratamentos com alfafa na dieta apresentaram menor custo total e maior lucro por litro de leite em relação ao confinamento (Tab. 6). 
A margem bruta foi positiva em todos os tratamentos, mas foi em média $45 \%$ maior nos sistemas baseados em pastagem, o que indicou menor desembolso para aquisição de insumos (principalmente concentrado proteico) e maior probabilidade de sobrevivência da atividade no curto prazo. Na análise da margem líquida, todos os tratamentos apresentaram resultado positivo, e isso indicou que a atividade tem possibilidade de se manter no longo prazo. Os melhores resultados foram dos tratamentos com pasto, em que a margem líquida foi aproximadamente $42 \%$ maior do que a do confinamento.

\section{CONCLUSÕES}

Concluiu-se que a substituição parcial da silagem de milho por pastejo restrito ou irrestrito de alfafa não limitou o desempenho produtivo dos animais e mostrou-se economicamente vantajosa em relação ao confinamento, nas projeções de curto e de longo prazo.

\section{REFERÊNCIAS BIBLIOGRÁFICAS}

\section{ANUÁRIO ESTATÍSTICO DA PRODUÇÃO ANIMAL. ANUALPEC. 2008. 220p.}

BARGO, F.; MULLER, L.D.; KOLLER, E.S. et al. Invited review: Production and digestion of supplemented dairy cows on pasture. J. Dairy Sci., v.86, p.1-42, 2003.

BUTLER, W.R. Relação entre a concentração de proteína da dieta, ambiente uterino e concepção em vacas leiteiras. In. NOVOS ENFOQUES NA PRODUÇÃO E REPRODUÇÃO DE BOVINOS, 2004, Uberlândia. Anais... Botucatu: Conapec Jr. (FMVZ-UNESP), 2004. p.101-109.

CASTILLO, A.A.; GALLARDO, M.R. Suplementación de vacas lecheras en pastoreo de alfalfa con concentrados y forrajes conservados. In: HITANO, E.H.; NAVARRO, A. (Eds). La afalfa en la Argentina. Buenos Aires: INTA Rafaela, 1995. p.197-204.

CASTILHO, A.R.; ONETTI, S.G.; GREGORET, F.R. Diagnóstico de dietas a partir de componentes de la leche: urea y corpos cetonicos. In: COMERON, E.A. (Ed). Articulos seleccionados sobre alfalfa en la alimentación de rumiantes. Buenos Aires: INTA Rafaela, 2007. p.43-52.
COMERON, E.A.; ROMERO, L.A. Utilización de la alfalfa por vacas lecheras em pastoreo. In: BASIGALUP, D.H. (Ed). El cultivo de la alfalfa en la Argentina. Buenos Aires: INTA Rafaela, 2007. p.303-331.

COMERON, E.A.; ROMERO, L.A.; ARONNA, M.S. et al. Respuesta productiva de vacas de raza Jersey y Holando em dos sistemas de alimentación. Produción y composición química de la leche. Rev. Arg. Prod. Anim., v.22, supl.1, p.41, 2002.

DAVIES, P.; MENDEZ, D. Meteorismo espumoso (empaste) en pastoreo. In: BASIGALUP, D.H. (Ed). El cultivo de la alfalfa en la Argentina. Buenos Aires: INTA Rafaela, 2007. p.389-404.

JAHN, E.; VIDAL, A.; SOTO, P. Sistema de producción de leche basado en alfalfa y maíz para la zona Centro Sur. Producción de leche. Agric. Tecn., v.60, p.43-51, 2000a.

JAHN, E.; VIDAL, A.; SOTO, P. Sistema de producción de leche basado en alfalfa y maíz para la zona Centro Sur. Consumo y calidad del forraje. Agric. Tecn., v.60, p.99-11, 2000b.

JOHNSON, A.D. Sample preparation and chemical analysis of vegetation. In: MANETJE, L. (Ed). Measurement of grassland vegetation and animal production. Aberustwyth: Commonwealth Agricultural Bureaux, 1978. p.96-102.

LOPES, M.A.; LIMA, A.L.R.; CARVALHO, F.M. et al. Controle gerencial e estudo da rentabilidade de sistemas de produção de leite na região de Lavras (MG). Cienc. Agrotec., v.28, p.883-892, 2004.

MATSUNAGA, M.; BEMELMANS, P.F.; TOLEDO, P.E.N. et al. Metodologia do custo de produção utilizada pelo IEA. Agric. São Paulo, v.23, p.123-139, 1976.

NOGUEIRA, A.R.A.; SOUZA, G.B. Manual de laboratório: solo, água, nutrição vegetal, nutrição animal e alimentos. São Carlos, SP: Embrapa Pecuária Sudeste, 2005. 334p.

NUTRIENT requirements of dairy cattle. 7.ed. Washington: National Academy of Sciences, 2001. 381p.

PRIMAVESI, O.; PRIMAVESI, A.C.P.A.; PEDROSO, A.F. et al. Microbacia hidrográfica do Ribeirão Canchim: um modelo real de laboratório ambiental. São Carlos, SP: Embrapa Pecuária Sudeste, 1999. 133p. (Boletim de pesquisa, 5). 
RODRIGUES, A.A.; COMERON, E.A.; VILELA, D. Utilização de alfafa em pastejo para alimentação de vacas leiteiras. In: FERREIRA, R.P.; RASSINI, J.B.; RODRIGUES, A.A. et al. (Eds). Cultivo e utilização da alfafa nos trópicos. São Carlos, SP: Embrapa Pecuária Sudeste, 2008. p.345-378.

SALADO, E.; COMERÓN, E.A.; SCHNEIDER, G. Evaluación productiva y económica de dos dietas contrastantes para vacas lecheras. In: REUNION ASOCIACION LATINOAMERICANA DE PRODUCCION ANIMAL, 20., 2007, Cuzco, Peru. Anais... Cuzco: ALPA, 2007. CD-ROM.

SKLAN, D.; ASHKENNAZI, R.; BRAUN, A. et al. Fatty acids, calcium soaps of fatty acids, and cottonseeds fed to high yielding cows. J. Dairy Sci., v.75, p.2463-2472, 1992.

TUPY, O.; ALVES, E. R. A.; ESTEVES, S. N. et al. Método para controle e análise de custos da produção de leite. São Carlos, SP: Embrapa Pecuária Sudeste, 2000. (Circ. técnica, 26).
VILELA, D.; CÓSER, A.C.; PIRES, M.F.A. et al. Comparação de um sistema de pastejo rotativo em alfafa com um sistema de confinamento para vacas de leite. Arch. Latinoam. Prod. Anim., v.2, p.6984, 1994.

VINHOLIS, M.M.B.; DE ZEN, S.; BEDUSCHI, G. et al. Análise econômica de utilização de alfafa em sistemas de produção de leite. In: FERREIRA, R.P.; RASSINI, J.B.; RODRIGUES, A.A. et al. (Eds). Cultivo e utilização da alfafa nos trópicos. Brasília: Embrapa Sede, 2008. p.395-420.

WILDMAN, E.E.; JONES, G.M.; WAGNER, R.L. et al. A dairy cow body condition scoring system and its relationship to selected production characteristics. J. Dairy Sci., v.65, p.495-501, 1982. 